\title{
Zoning of the Territory of Russia According to the Efficiency of the Use of Low-Grade Ground Heat for Heating.
}

\author{
VasilyevG.P. ${ }^{\mathrm{a}, 1,3}$, PeskovN.V. ${ }^{\mathrm{b}, 1,2}$, Gornov V.F. ${ }^{\mathrm{c}, 1}$, Kolesova M.V. ${ }^{\mathrm{d}, 1}$ Yurchenko I.A. ${ }^{\mathrm{e}, 1}$ \\ ${ }^{1}$ JSC "INSOLAR-INVEST", Moscow, Russia \\ ${ }^{2}$ Faculty of Computational Mathematics and Cybernetics, Lomonosov Moscow State University, Moscow, Russia \\ 3JSC "NIIMosstroy", Moscow, Russia
}

\begin{abstract}
This paper reports the results of study on the effectiveness of using low-grade ground heat in heat pump systems under the climatic conditions of Russia. The study was performed using the software package "INSOLAR.GSHP.12", which simulates the non-stationary thermal conditions of ground source heat pumps (GSHPs) over several years of operation. The paper presents the results of the zoning of the territory of Russia according to the effectiveness of using low-grade ground heat in heat pump systems. The zoning was performed with consideration of the decrease of the soil temperatures over several years of heat collection system operation. The soil temperatures expected on the fifth year of operation were considered to be the design temperatures. The described study was performed with the financial support of the Ministry of Education and Science of Russia. Contract ID RFMEFI57914X0026.
\end{abstract}

\section{Introduction.}

Currently, ground source heat pumps (GHSPs) are widely used in regions with moderate climates [1]. Unlike Russia, these regions have higher natural soil temperatures and relatively short heating seasons. These conditions make ground heat collection from soil at temperatures above zero possible.

During GSHP operation, the body of soil surrounding the ground heat exchanger is subject to multiple freezing and thawing events. Naturally, such events alter the state of matter of moisture contained in soil pores, which is generally present in liquid, solid, and gas states simultaneously.

One way to allow effective use of GSHP in climatic conditions of Russia is to zone the territory of the country, determing the effectiveness of GSHP usage in different zones.

\section{Zoning of the territory of Russia.}

Zoning of the territory of Russia according to the efficiency of the use of low-grade ground heat for heating was performed to estimate the efficiency of using a GSHP system in Russian climatic conditions. Zoning was based on the results of numerical experiments (1)

\footnotetext{
${ }^{\mathrm{e}}$ Corresponding author: iyurchenko@insolar.ru

aPVassiliev@mail.ru,

beskovnick@gmail.com,

insolar-invest@yandex.ru,

deco-insolar@mail.ru,
}

Within the experiment, we considered:

- the heat collection system with low a consumption of ground heat density - a horizontal heat collection system made of polyethylene pipes $400 \mathrm{~m}$ in length and $0.05 \mathrm{~m}$ in diameter.

- the heat collection system with a high consumed ground heat density - a vertical heat collection system having one borehole $40 \mathrm{~m}$ in length and $0.16 \mathrm{~m}$ in diameter.

The research indicated that by the end of the heating season, the consumption of thermal energy from a body of soil causes the soil temperature to decrease around the heat exchanger, which cannot be fully restored through the summer in the Russian climate on almost all territories of Russia; therefore, by the beginning of the next heating season, the thermal potential of the soil is reduced. The consumption of thermal energy through the next heating season causes further temperature reduction, so by the beginning of the third heating season, the thermal potential is reduced even more. In addition, this trend persists. The envelopes of the thermal impact of longstanding heat collection system operation on natural ground thermal conditions are exponential; therefore, by the fifth year of operation, the soil enters a new, almost periodical, temperature cycle [5]. That is why the soil's temperatures expected on the fifth year of operation were 
considered as the design temperatures. Taking the temperature behavior into consideration, for the purposes of zoning Russian territory according to the effectiveness of GSHP operation,the average coefficient of performance (COP) - $K^{r}$ tr of the fifth year of operation was considered as the criterion of efficiency of the GSHP operation. The COP represents the ratio of the useful thermal energy produced by the GSHP to the electrical energy consumed by the GSHP.For an ideal Carnot cycle, the COP can be represented as:

$K_{t r}=\frac{T_{o}}{T_{o}-T_{i}}$,

Where:

$T_{o}$ - temperature potential of the heat transferred to the heating system, $K$;

$T_{i}$ - temperature potential of the source of heat, $K$.

The coefficient of performance of a heat pump $K_{t r}$ is the ratio of the useful heat transferred to.

The numerical experiments were performed using "INSOLAR.GSHP.12", which calculates the optimal operation parameters for a heat collection system, depending on the climatic conditions of a region, the thermal insulation of a building, the individual operational parameters of a heat pump, the circulation pumps, the heating system equipment, as well as the operative conditions. The software is based on the abovementioned method of simulation of thermal conditions of low-grade ground heat gathering systems that bypasses the difficulties associated with the approximation of the external impacts on the heat collection system as well enables the use of data on the soil's natural thermal conditions obtained from weather stations. The software partially accounts for the whole range of factors (such as the presence of the groundwater, it's speed and thermal conditions, the structure and location of the soil layers, the "thermal" background from the Earth, the precipitation, the phase transformation of moisture in the pore space, and more) that have a significant influence on the formation of the thermal regime of the tunnel but that are almost impossible to account for simultaneously. The data, obtained from the weather stations was used as a solution of the "base" problem.

The results of the zoning of the territory of Russia, according to the effectiveness of use of low-grade ground heat for heating of buildings, are presented in figs. 1-4.

\section{RUSSIA TERRITORY ZONING ACCORDING TO EFFECTIVENESS OF USING UPPER SOIL LAYERS HEAT ENERGY FOR HEATING AND COOLING}

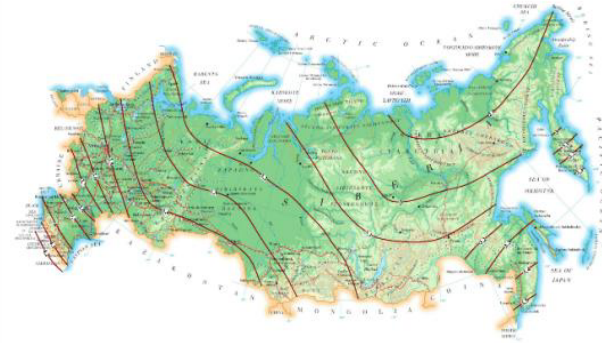

Horisontal GSHP

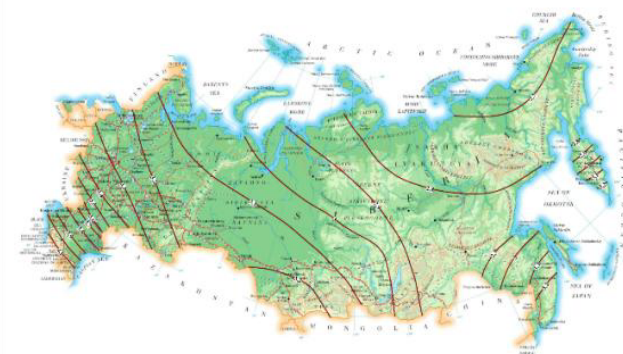

Vertical GSHP

Figure.1 Isolines on the map represent the value of energy conversion coefficient for "horizontal" GSHP, equalling the ammount of useful thermal energy produced by gshp on consuming $1 \mathrm{kw}$ of electrical energy, [unit fractions]

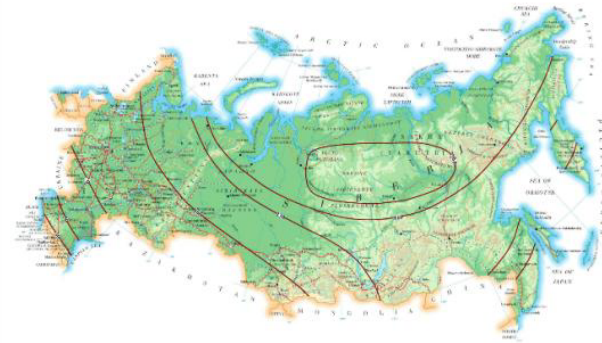

Horisontal GSHP

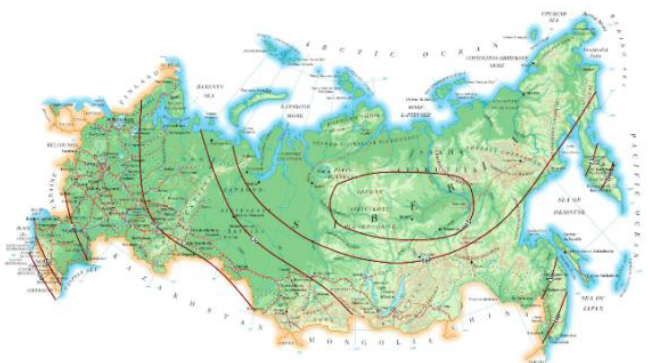

Vertical GSHP

Figure.2.Isolines on the map represent specific annual energy consumption of GSHP+PTU, including heating, cooling, ventilation and hot water supply, per one sq.m. of heated area, $k W \times h /\left(y e a r \times m^{2}\right)$ 


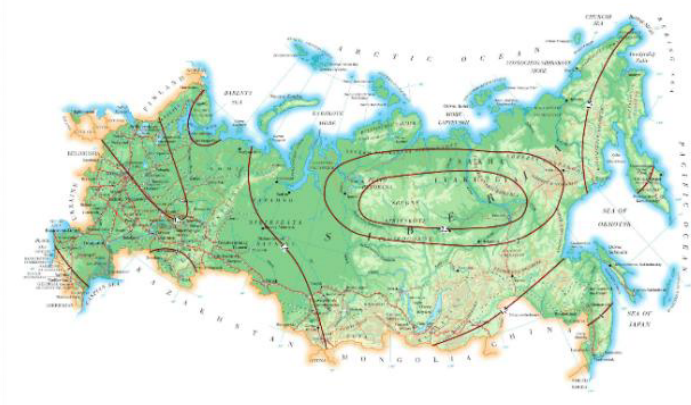

Horisontal GSHP

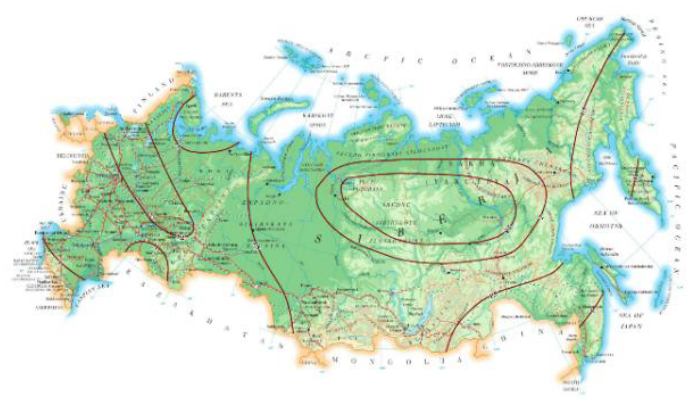

Vertical GSHP

Figure.3.Isolines on the map - a rational correlation of thermal power of peak terminal unit and supplyed electrical power of the GSHP, [unit fractions]

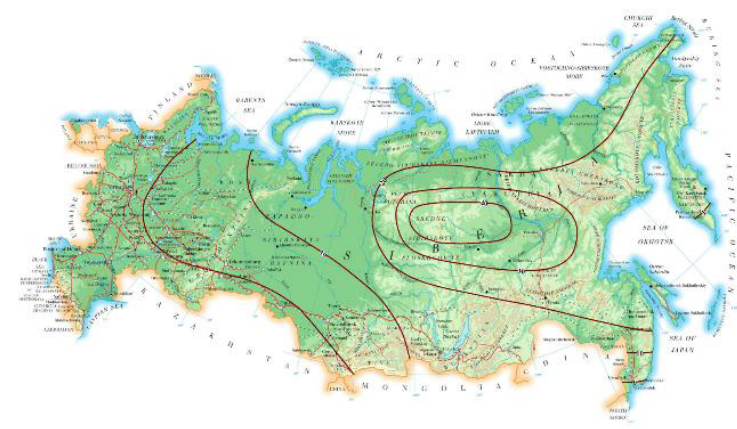

Horisontal GSHP

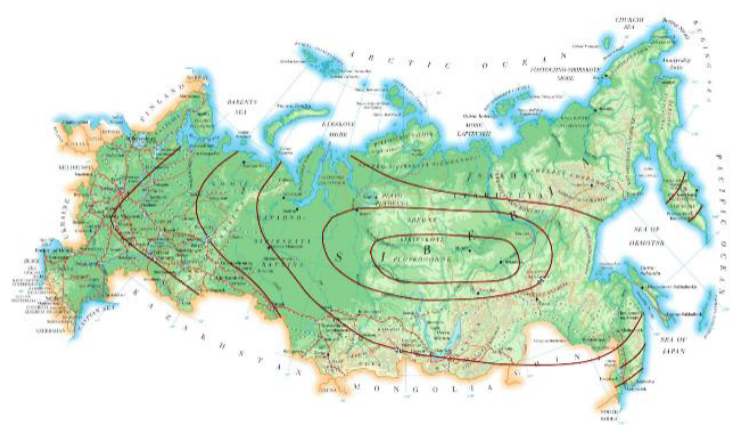

Vertical GSHP

Figure.4.Isolines on the map represent the specific weight thermal energy, produced by the peak terminal unit (PTU) in the total energy consumption of the GSHP+PTU system, [percent]

Fig. 1 shows the values and isolines for the COP of a GSHP. The maximum values of $K^{r}$ is 4.24 for the horizontal and 4.14 for the vertical heat exchangers are to be expected in the south of Russia, and the minimal values of 2.87 and 2.73 are expected in the North. In Central Russia, the values of $K^{r}{ }_{t r}$ vary from 3.2 to 3.6. Remarkably, that the Russian Far East, which is region of traditionally lacking fuel, exhibits sufficiently high $K_{t r}^{r}$ values of (3.2-3.5). Apparently, the Far East is a region of priority for GSHP implementation.

Fig. 2 shows the values and isolines of the specific annual energy consumption of a GSHP+PTU (peak terminal unit), including heating, cooling, ventilation and hot water supply, per sq.m. of the heated area. The specific annual energy consumption of the "horizontal" GSHP varies from $28.8 \mathrm{~kW} \cdot \mathrm{h} /\left(\right.$ year $\left.\cdot \mathrm{m}^{2}\right)$ in the south of Russia to $241 \mathrm{~kW} \cdot \mathrm{h} /\left(\right.$ year $\left.\cdot \mathrm{m}^{2}\right)$ in Yakutsk and for the vertical GSHP from $28.7 \mathrm{~kW} \cdot \mathrm{h} /\left(\right.$ year $\left.\cdot \mathrm{m}^{2}\right)$ in the south of Russia to $248 \mathrm{~kW} \cdot \mathrm{h} /\left(\right.$ year $\left.\cdot \mathrm{m}^{2}\right)$ in Yakutsk. By multiplying this value for each region by the COP for each region $K^{r}{ }_{t r}$ reduced by 1 , we obtain the amount of energy saved by the GSHP per sq.m. per year. For example, in Moscow, the amount saved would be 189.2 $\mathrm{kW} \cdot \mathrm{h} /\left(\right.$ year $\left.\cdot \mathrm{m}^{2}\right)$ (for a vertical GSHP).

Fig. 3 shows the values and isolines for a rational correlation of the thermal power of a peak terminal unit and the supplied electrical power of a GSHP in unit fractions. It can be seen that the rational correlation of the thermal power of the PTU and the electrical power of the GSHP (without the PTU) varies from 0 in the south of Russia to 2.88, for the horizontal GSHP and is up to 2.92 for the vertical GSHP in Yakutsk. This result should be studied further.

Fig. 4 shows theisolines of the specific weight of thermal energy produced by the peak terminal unit (PTU) in the total energy consumption of the GSHP+PTU system, in percent. It varies from $0 \%$ in the south of Russia to $38-40 \%$ in Yakutsk and Tura for "horizontal" systems and $48.5 \%$ in Yakutsk for vertical systems. In Central Russia, these values are in the range of 5 to $7 \%$ for both the horizontal and the vertical GSHP systems. These values are rather low power inputs, so the PTU should be chosen with care. Most effective with respect to the initial costs per $1 \mathrm{~kW}$ of power are electric PTUs.

[键入文字] 


\section{Conclusions}

In conclusion, the following should be mentioned regarding the problem of the correct choice of thermal insulation of a building. Determining the thermal insulation is a complicated problem, and its solution requires numerical analysis, taking into account the Russian climate and the specifics of the used engineering equipment, the grid infrastructure, the always decreasing ecology in cities, and so on. Obviously, it is incorrect to form any requirements regarding the walling of a building without considering its correlation with the climate, the energy saving system, the utilities and so on. Therefore, in the immediate future, solving this problem of insulation would be possible only through regarding the system of building + energy saving system + climate + environment as a whole ecoenergy system; such a concept makes the competitive advantages of GSHP in Russia difficult to overestimate.

\section{Acknowledgements:}

This paper contains the results of research performed with financial support from the Ministry of Education and
Science of the Russian Federation on the subject of the «Development of principles and methods for creating adaptive Ground source heat pumps, harmonized with power load cycles of heated or cooled facilities», contract ID RFMEFI57914X0026.

\section{References}

1. LundJ.W., Freeston D.H., Boyd T.L. Direct utilization of geothermal energy 2010 worldwide review. Geothermics, 40 (2011) 159-180.

2. Vasilyev G.P. Heat and cold buildings and structures using low-grade heat energy of the surface layers of the Earth (Monograph). Publishing house "Border". M., "Red Star" -2006. -220.

3. Gupta S.C. The classical Stefan problem: basic concepts, modeling and analysis. Elsevier, 2003.

4. Yang H., Cui P., Fang Z. Vertical-borehole groundcoupled heat pumps: A review of models and systems, Applied Energy, 87 (2010) 16-27.

5. Sanner B. Ground Heat Sources for Heat Pumps (classification, characteristics, advantages). Course on geothermal heat pumps, 2002. 